\title{
Effect of Mobile- Based Educational Program through Bluetooth and WhatsApp. Application on the Oral Health Values, Dental Literacy, and Oral Self-Efficacy among Older Adults. Marwa Ibrahim Mahfouz Khalil ${ }^{1}$, Dina Metwally Sorour ${ }^{1}$, Enas Fouad Sayed Mousa ${ }^{2}$, Reem Said Shaala ${ }^{3}$
}

(1) Department of Gerontological Nursing, Faculty of Nursing, Alexandria University, Egypt.

(2) Department of Geriatric Medicine, Faculty of Medicine, Helwan University, Egypt

(3) Department of Geriatric Medicine, Faculty of Medicine, Alexandria University, Egypt

\section{Corresponding author}

Name: Marwa Ibrahim Mahfouz Khalil, Assist. Prof. of Gerontological Nursing

Email: marwa871975@gmail.com

Tel No: 01270202044

\section{Abstract}

Background: With the advent of preventive dentistry and an expanded array of treatment options, the possibility of maintaining oral health throughout the life span has increased. This interdependence between oral health and general well-being further validates the need to explore factors related to the improvement of the oral health status of community-dwelled older adults. Essential to the process of enhancing the oral health status of this segment is the exploration of the numerous variables which must be considered in the development of mobile-based educational program. Thus, the adequate assessment of the health values, literacy, and perception related to the performance of oral hygiene is of upmost importance. Only then effective elder-specific oral interventions could be developed and implemented. Aim: The purpose of this quasi-experimental study was to measure the effect of mobilebased educational program through Bluetooth and WhatsApp Application on the oral health values, dental literacy, and oral self-efficacy among older adults. Setting: The study was conducted in El-Wafaa club of elderly persons affiliated to the Ministry of Social Solidarity. Subjects: A 67- participant, own smart phones, able to download and deal with related software applications, and capable of reading sent messages were operationalized using four specified tools. Tools: These were (1) Developed Demographic and Oral Health Profile for the Older Adults Structured Interview Schedule, (2) Health Literacy in Dentistry Scale (HeLD- short form), (3) Oral Health Values Scale (OHVS), and (4) Geriatric Self- Efficacy Scale for Oral Health (GSEOH). Results: Initially revealed that the higher prevalence of mouth health problems was related to tooth decay $(64.2 \%)$ and tooth plaque $(62.7 \%)$. Oral health problems had mostly a negative impact on satisfaction with fluids drinking and mouth appearance ( $40.3 \%$ each). There was a highly statistical positive significant improvement in the older adults' oral-related literacy, values, and efficacy post-program than before. A strong positive significant correlation was proved between the studied variables along the whole implementing periods. Oral health literacy was a predicting / independent factor for both SelfEfficacy and values in each period of interventions. Conclusion: The proposed program succeeded in improving the main studied variables' subscales with different degrees as represented by the mean percent scores, immediately after application that decreased at a 3week follow up of mobile-based oral care implementation but still significant compared with the pre- intervention period. Recommendations: Digital or e-health interventions to prevent or rectify oral problems of older adults should be wide-ranging and multi-faceted to be conducted via the social networks and invest in mobile health clinics. Design a preventive program to target older adults living in Egypt, through increasing access and minimize barriers to treatment for elderly with low financial standard and collecting systematic data on 
oral health status as well as general medical conditions to be monitored and included in national oral health promotion plans for older adults.

Keywords: Oral health literacy, oral health value, geriatric oral self-efficacy, mobile- based educational program, older adults.

\begin{tabular}{|l|l|l} 
Received : $1 / 10 / 2020$ & Accepted $:$ 15/11/2020 & Published : $1 / 12 / 2020$ \\
\hline
\end{tabular}

\section{Introduction}

Oral health is an important part of "Active Aging" and is considered one of the three basic pillars of general health and wellbeing of older people ${ }^{[1]}$. The estimation of the Global Burden of Disease Study (2017) reflected that oral diseases affected close to 3.5 billion people worldwide, with caries of permanent teeth being the most common condition ${ }^{[2]}$. Oral health goes beyond good teeth to the functioning of the whole craniofacial complex that positively affects enjoyment of life ${ }^{[3]}$. Frequency of age - associated oral dysfunctions varies across nations. The disparities might result from the reality that these disorders are multifactorial in nature including biological, behavioral, and circumferential factors ${ }^{[4]}$. However, there is a consensus that greater proportions of seniors (65-74 years) exhibited periodontal pockets of 6 $\mathrm{mm}$ or above compared with adult populations in both developed and developing countries ${ }^{[5]}$.

Oral health diseases increase steadily as age and chronicity level heightened and confined to tooth loss, dental caries, periodontal disease, xerostomia, and oral cancers ${ }^{[6]}$. Oral difficulties are hidden, neglected, and undervalued among a large proportion of elderly settled in community which triggers a serious of other problems and responsible for considerable poor dietary intake and weight loss from inappropriate chew, discomfort, disrupts sleep, and the inability to relax ${ }^{[7]}$. They also affect an older person's appearance, self-esteem, and selfconfidence as well as their ability to talk and communicate effectively. They are responsible for higher in-hospital mortality and could threaten the maintenance of independence; the last is the fundamental goal for elderly care ${ }^{[8,9]}$.

Oral cavity physiological changes (e.g., decreased salivary gland function), as well as a range of systematic diseases as cardiovascular diseases, respiratory diseases, and strokes with adverse effects of their treatments increase susceptibility to oral diseases in older adults ${ }^{[10]}$. The risk of poor oral health issued when older people become less able to self-manage due to functional dependence, physical frailty, medical co-morbidity, and cognitive impairment ${ }^{[11]}$. Fortunately, many of these oral diseases can easily be prevented by adequate access to preventive/ restorative dental care and compliance with daily oral hygienic practices ${ }^{[12]}$.

Elderly people worldwide suffer from poor access to dental health care services and visit the dentist irregularly due to impaired mobility, poor public transport, and financial hardship particularly for those who reside in rural areas. As stated by results from the World Health Survey (2012), access ranges from 35\% in low-income countries to $60 \%$ in lowermiddle-income countries, $75 \%$ in upper-middle income countries and $82 \%$ in high-income countries ${ }^{[13]}$. Moreover, as people age, oral hygiene practice become more difficult because of impaired vision, lower tactile thresholds, cognitive impairment, reduced dexterity, and frailty ${ }^{[14]}$. Furthermore, limited oral health literacy, little value for oral health, and low selfefficacy act as barriers for maintaining and promoting oral health in older adults ${ }^{[6]}$.

Oral health literacy is realized as the degree to which individuals have the capacity to obtain, process, and understand the basic health information and services needed to make oral health- related decisions ${ }^{[15]}$. Limited oral health literacy hinders older adults from 
understanding dental advice presented to them and inhibits effective communication with dental health care professionals, which widen un-doubtfully the gap between dental knowledge, behavior, and practice. It was reported that older adults in common have lower oral health literacy skills compared to their younger counter partners ${ }^{[16]}$.

Oral health values have been closely related to treatment-seeking behaviors, as attending dental appointments, and engaging in preventive oral care because values provide older people with standards for behavior to reach optimum oral haleness based on the perceived magnitude of a certain oral health comportment. Oral health values are wellacquainted as the extent to which one views dental status as important or meaningful, by dedication to improve or maintain one's teeth, gingiva, and other aspects of orofacial functioning" ${ }^{[17]}$. Regrettably, older people head to drive supplementary attention to treating their systematic comorbidities rather than oral disorders, despite the possibility that, at such life juncture, the oral health troubles are aroused and triggered ${ }^{[18]}$. Moreover, misperceptions and myths that tooth loss and oral diseases are naturally associated and rather accepted with growing old is greatly evidenced. In consequence, dental visits are stepped for just urgent painful snag, rather than for monotone screening or preventive benefits ${ }^{[6]}$.

Oral Self- efficacy of older adults mostly expressed the dependability of one's capability and strength to conduct and master the situation through executing successful preventive oral health act; used to determine whether an approaching oral health-related behavior is sponsored, and to what extent continue against any obstacles that may encounter. The target is adopting older adults' oral self-auspices and augmenting confidence in ability to prevent oral health conflicts ${ }^{[19,20]}$.

Ameliorating oral hygiene of older adults is a base nationwide and global seniority and this aspiration could be bringing to fruition through oral health interventional procedures. Changing the idea of acceptance of dental problems as normal as one ages is more important than the interventions taken to prevent it. Reduction of the poor oral cavity should not be assumed to just adapt action to avoid dental problems, practice oral hygiene or use oral health services. Emphasis should extend much broader to change elders' decision, choices, healthseeking behaviors, and perceived capabilities in dental management by exploring the most contributing behavior, practice, skills, and knowledge- related factors ${ }^{[21,22]}$. Nowadays, the extraordinary proliferation of mobile devices offers a promising strategy for reaching the older adults in the community to deliver oral health promotion programs. Providing oral health education by using mobile phones digital programs is an effective and inexpensive delivery channel for facilitating the preventive measures of oral health problems ${ }^{[23]}$. All health care professionals should work in collaboration with each other to promote oral health for the older adults. This holds true with respect to the gerontological nurses and geriatric physicians as well to play a key role in assisting and supporting the elderly persons to achieve and maintain optimum welfare through determining oral care needs, develop individualized care plans, provide clinical hygiene treatment, make referrals to dentists, and implement oral awareness programs ${ }^{[24]}$.

\section{Significance of the study:}

The advancement in technology aids with the higher rate of using especially in today's elder everyday chores and health, shed the light toward the initiation of digital educational program concerning such sophisticated areas of dental profile, and which enrolled for the first time in a study concerning this vital and unfortunately neglected dimension of elders' wellbeing. No previous studies in Egypt, to the best of our knowledge, touch the variable of oral health value, oral literacy, and self-efficacy in older adults or planning e-health program 
target the elderly group, with even scarce studies published internationally. Virtual program is updated line of preventive and management levels of oral health in older adults with advantages to be available all time, when needed, easily reachable, affordable, and accommodate to the unique needs and suitable to every raised oral and dental conflicts.

\section{Research Aim:}

This study was conducted to introduce and pilot an innovative digital program of oral health promotion into the care of community-dwelled older adults. The purpose was to measure the effect of mobile- based educational program through Bluetooth and WhatsApp application on the oral health values, dental literacy, and oral self-efficacy among older adults that they can carry out or engage in healthy oral behaviors.

\section{Research Hypothesis}

Community dwelling older adults who receive the proposed mobile- based educational strategies exhibit higher oral health values, dental literacy, and oral self-efficacy post the interventions than before.

\section{Materials and Method}

\section{Materials}

\section{I- Design:}

A pre- and post- quasi-experimental research design was used.

\section{II- Setting and Subjects:}

The study was conducted in El-Wafaa club of elderly persons in Alexandria, Egypt; affiliated to the Ministry of Social Solidarity; after investigating of all clubs by the researchers. The selection based on: (1) higher attendance rate (ranged between 10 to 12 elders daily), (2) higher registered rate (402 elders according to the club records at the time of study conduction), (3) representing different sectors in Alexandria, and (4) with daily 6working hour for 6 days weekly except Fridays. During data collection, target population of male and female older adults attending the previously mentioned setting were selected and investigators conducted a baseline in-person interview of the subjects to gather information on oral health conditions of the verified sample.

\section{III- Sample size calculation and sampling technique:}

The Epi info program V 7.0 was used to estimate the sample size based on the following parameters: (Target population size $=402$, Expected frequency $=50 \%$, Acceptable error $=10 \%$, Confidence coefficient $=95 \%$, Power analysis $=80 \%$ ). Sample size amounted to 60 . Ultimately, after adding $10 \%$ for defaulter subjects, a total of 67 male and female older adults' subjects were chosen based on age (60 years or older), perform independently oral care, have and able to use smart phones in addition to read sent messages from these mobiles, capable mentally of engaging in a clear and logical conversations, able to download and deal with related software applications, and accepted and interested to participate in the study and share in the digital educational sessions. The study subjects were selected by the probability sampling (using systematic sampling method). This was done by numbering each element of the population from 1 to 402, and then choosing every 6th individual to be a part of the sample (Total population/sample size $=402 / 67=6$ ), through automated process using number generating software. 
IV- Tools:

Four tools were used for data collection.

Tool I: - Developed demographic and health profile for the older adults structured interview schedule. It consists of two parts:

\section{Part I:}

- The demographic characteristics of the study subjects such as age, sex, marital status, educational level, job before retirement and income.

Part II: The oral health profile of the older adults

- Assessment of the oral hygiene practices of the older adults explored common dental problems. frequency and duration of tooth brushing and use of dental floss.

- Assessment of impact of oral health problems on the subject's ability to masticate, communicate, and to consume hot and cold drinks.

\section{Tool II: - Health Literacy in Dentistry scale (HeLD)- short form.}

HeLD-14 (Jones et al., 2015) ${ }^{[25]}$ derived from HeLD-29 (Jones et al., 2013) ${ }^{[26]}$, to measure oral health literacy on a 5-point Likert-type scale ranging from "without any difficulty" (4) to "unable to do" (0). The scale has seven subscales: receptivity, understanding, support, economic barriers, access, communication, and utilization. The possible score range was $0-56$, with higher scores indicate higher levels of oral health literacy (Table 1a, 1b).

Table (1a): Percent score of Health Literacy in Dentistry scale

\begin{tabular}{|c|c|c|c|c|c|}
\hline \multirow{2}{*}{ Score } & 0 & 1 & 2 & 3 & 4 \\
\cline { 2 - 5 } & $\begin{array}{c}\text { Unable to } \\
\text { do }\end{array}$ & $\begin{array}{c}\text { Very } \\
\text { Difficult }\end{array}$ & $\begin{array}{c}\text { With some } \\
\text { Difficulty }\end{array}$ & $\begin{array}{c}\text { With little } \\
\text { Difficulty }\end{array}$ & $\begin{array}{c}\text { Without } \\
\text { any } \\
\text { Difficulty }\end{array}$ \\
\hline
\end{tabular}

Table (1b): Subscales Scoring system of Health Literacy in Dentistry scale

\begin{tabular}{|l|c|c|}
\hline \multicolumn{1}{|c|}{ Items } & No. of items & Score \\
\hline $\begin{array}{l}\text { Health Literacy in Dentistry scale } \\
\text { (HeLD) subscales: }\end{array}$ & $\mathbf{1 4}$ & $\mathbf{0 - 5 6}$ \\
\hline Receptivity & 2 & $0-8$ \\
\hline Understanding & 2 & $0-8$ \\
\hline Support & 2 & $0-8$ \\
\hline Economic barrier & 2 & $0-8$ \\
\hline Access & 2 & $0-8$ \\
\hline Communication & 2 & $0-8$ \\
\hline Utilization & 2 & $0-8$ \\
\hline
\end{tabular}




\section{Tool III: - Oral Health Values Scale (OHVS)}

A 30-item with a 5-point Likert scale (ranging from "strongly disagree=1" to "strongly agree $=5$ "), designed by Edwards $(2017)^{[27]}$ to measure the degree to which one demonstrates investment in improving or maintaining oral health by assessing an individual's degree of perceived importance of good oral health and healthy dental behaviors, put into consideration inverse valued items. All scale items were distributed into six factors (importance of seeking professional dental care, importance of overall oral health and appearance, importance of flossing behaviors, importance of retaining natural teeth, concerns about the impact of oral health on appearance, and importance of brushing behaviors). Total score ranged from 30 to 150 , with higher scores indicating greater oral health value (Table $2 a, 2 b$ ).

\section{Table (2a): Percent score of Oral Health Values Scale}

\begin{tabular}{|c|c|c|c|c|c|}
\hline \multirow{2}{*}{ Score } & $\begin{array}{c}\text { Strongly } \\
\text { Disagree }\end{array}$ & Disagree & Neutral & Agree & $\begin{array}{c}\text { Strongly } \\
\text { Agree }\end{array}$ \\
\cline { 2 - 6 } & 1 & 2 & 3 & 4 & 5 \\
\hline
\end{tabular}

Table (2b): Factors Scoring system of Oral Health Values Scale

\begin{tabular}{|l|c|c|}
\hline \multicolumn{1}{|c|}{ Items } & No. of items & Score \\
\hline Factors of Oral Health Values Scale: & $\mathbf{3 0}$ & $\mathbf{3 0 - 1 5 0}$ \\
Importance of seeking professional dental care & 8 & $8-40$ \\
Importance of overall oral health and appearance & 7 & $7-35$ \\
Importance of flossing behaviors & 4 & $4-20$ \\
Importance of retaining natural teeth & 4 & $4-20$ \\
concerns about the impact of oral health on appearance & 3 & $3-15$ \\
Importance of brushing behaviors & 4 & $4-20$ \\
\hline
\end{tabular}

\section{Tool IV: - Geriatric Self- Efficacy Scale for Oral Health (GSEOH)}

A reliable and valid twenty-item scale, developed by Ohara et al., (2016) ${ }^{[28]}$ and used to evaluate self-efficacy in the context of oral health among older adults to measure three dimensions of personal beliefs about oral functioning (9 statements), oral hygiene habits (8 statements), and dental visit (3 statements). Older adults rate these statements on a four-point Likert scale $(1=$ not confident at all to $4=$ very confident). Total score of this index ranged from 20 (the minimum) to 80 (the maximum) with higher score indicated a high level of oral health-related self-efficacy (Table 3a, 3b).

Table (3a): Percent score of Geriatric Self- Efficacy Scale for Oral Health

\begin{tabular}{|c|c|c|c|c|}
\hline \multirow{2}{*}{ Score } & $\begin{array}{c}\text { Not Confident } \\
\text { At All }\end{array}$ & A Little Confident & $\begin{array}{c}\text { Moderately Confide } \\
\text { nt }\end{array}$ & $\begin{array}{c}\text { Very } \\
\text { Confident }\end{array}$ \\
\cline { 2 - 5 } & 1 & 2 & 3 & 4 \\
\hline
\end{tabular}


Table (3b): Dimensions Scoring system of Geriatric Self- Efficacy Scale for Oral Health

\begin{tabular}{|l|c|c|}
\hline \multicolumn{1}{|c|}{ Items } & No. of items & Score \\
\hline $\begin{array}{l}\text { Dimensions of Geriatric Self- Efficacy } \\
\text { Scale for Oral Health (GSEOH): }\end{array}$ & $\mathbf{2 0}$ & $\mathbf{2 0 - 8 0}$ \\
Personal beliefs about oral functioning & 9 & $9-36$ \\
Oral hygiene habits & 8 & $8-32$ \\
Dental visit & 3 & $3-12$ \\
\hline
\end{tabular}

\section{Method}

- An official letter was forwarded to the director of El Wafaa club in order to obtain approval to carry out the study and collect the necessary data from the study subjects using the designed tools after a thorough review of literature.

- Tools (II, III, IV) were translated into Arabic language and presented to a panel of five experts for content validity in the fields of Gerontological Nursing, Geriatric Medicine, Prosthodontics, Periodontics, and Endodontics. The reliability for tool II using test - retest measurement $r$ was 0.874 , tool III 0.839 and for tool IV was 0.851 (applied to 7 older adults attended the setting). A pilot study was carried out on six older adults attended at the club and were excluded from the study subjects.

\section{Preparation Period}

- A baseline oral health assessment of older adults in the club using the study tools (II to IV) was conducted prior to the commencement of the presentation. After the baseline face to face interview, program objectives were discussed and contents were scheduled, in addition to obtaining WhatsApp contact numbers under confidentiality of not shared outside the groups from any member including the researchers as well. Elders were instructed to rename their phones, meaning replace the phone brand with their names, to be easily identified when shared the contents with them through Bluetooth, and ensure content security as not to be exchanged outside the structured concerned groups.

\section{Application period}

- A four-week training program was presented in 8 sessions (two sessions per week for each group). Each of these sessions took about 12-15 minutes maximum using very simple statements and techniques to be understood and taken into consideration the attention span of older adults. The subjects distributed into small groups (7 groups in total; each group contains between 8-11 senior members) throughout the program application. The elders were assigned to the corresponding groups randomly and notified weekly with the content and meeting through WhatsApp groups. 
- The sessions flowed as the following; First session: covered items related to (Importance of oral health, and its indicators, basic components of the oral cavity), Second session: (Age-related changes in the oral cavity, risk factors for oral health problems in older adults, gingivitis; causes, manifestations, and management), Third session: (Tooth decay; causes, stages, complication, and how to prevent it, halitosis; causes, and management, dry mouth; causes, manifestations, and management), Fourth session: (Tooth sensitivity; causes, manifestations, and management, tooth brux; causes, manifestations, and management, dental neuritis; causes, manifestations, and management), Fifth session: (First aids for tooth fractures, mouth ulcer; causes, manifestations, and management, oral cancer; manifestations), Sixth session: (Steps of tooth brushing, how to care for tooth brush), Seventh session: (Steps of tooth flossing, components of healthy food to maintain oral health) and Eighth session: (How to care of dentures, guidelines to prevent oral health problems in older adults, steps of self-examination to oral cavity).

- During the sessions, the investigators represented the content via audio presentation of the theoretical parts for 10 minutes average, then, the practical sections sent digitally in form of brief videos of no more than 5 minutes duration across the smart phone Bluetooth app. The audio presentations illustrated all basic information regarding the oral health, ageinduced changes, oral-friendly nutrition, and preventive strategies with illustrative pictures to clarify materials provided in the program., while short-duration videos demonstrating the accurate steps of tooth brushing, flossing, and care of dentures.

- Each elder had a chance, mean after, to watch sent file as emulation of learnt procedure, redemonstrated of each main practice 5 minutes post-session to ensure mastering, then had ample time later to ask questions for further clarification and correction of malpractice through scheduled WhatsApp meeting at time suitable for all group members. Group discussion and feedback through messages and audio were allowed between all members.

\section{Evaluation period}

- For creating a motivational education environment for older adults, the investigators checked the learning outcome of the participants after each session using "Kahoot platform" as the most interactive, flexible, very interesting, and easy to use game-based learning platform. Elders were guided to register to Kahoot.com, login to the account, enter the Pin code shared by the researchers in Kahoot Quiz Page and enter a nickname. At the end of each question and once the oral game over, the leaderboard displayed the top five scorers by results and rank. Winners are reinforced by prizes and honorary board published on the group page to promote more and better engagement through successful competitions. Then, a summary was given by the researchers, emphasizing the most important points to make sure the older adult understood and followed the given instructions.

- Comparison was done between pre- and post- tests using proper statistical analysis to evaluate the effectiveness of the program on the oral self-efficacy, oral health values and oral health literacy among community dwelling older adults. 
- Educational booklet in a simple Arabic language with colored images and large font to accommodate age-related visual changes to improve the learning process was developed by the researchers and given to each elderly participated in the study after rehearsal of recent linked literatures $[14,16,22,23,29]$.

- The data collection started on the first of March 2019 to the end of November 2019 in which both older adults and associated informal caregivers (family members) were included in the knowledgeable and practical sessions.

\section{Ethical considerations: -}

An ethical approval from the Research Ethical Committee confirming the legality of the research is obtained. An informed written consent was obtained in the initial meeting from each study subject included in this study after being notified with the purpose of the study and desire of withdrawn from the study at any time was respected. Anonymity and privacy of the study subjects was maintained, and confidentiality of the collected data was assured.

\section{Limitations of the study:}

During the different phases of the study, seven older adults did not complete the study for any predetermined reasons who replaced by others to maintain the sample size.

\section{Statistical analysis of the data}

Statistical analysis was done by using Statistical Package of Social Science "SPSS" software version 20.0. Statistical significance was considered at the level of $\mathrm{P}$ at $\mathrm{p} \leq 0.05$. Number and percentage were used for describing and summarizing the qualitative data. Whereas, arithmetic mean (x), standard deviation used for describing central tendency and dispersion of the quantitative data. Analysis of variance (ANOVA) used to compare the mean difference of normally distributed quantitative variables within the same group in different periods, significance between periods was done using Post Hoc Test (adjusted Bonferroni), Pearson coefficient (to correlate between two normally distributed quantitative variables) and Regression (to detect the most independent factor affecting Geriatric Self- Efficacy, Oral Health Values, Health Literacy in Dentistry).

\section{Results}

Table (4) showed that the study subjects' age ranged between 60 and 82 years with a mean of $70.12 \pm 6.20$ years and the upper hand of females sharing [more than three fifths $(61.2 \%)]$. Those subjects who married (77.6\%), had secondary education (61.2\%), and were employed before retirement and did not have enough income $(58.2 \%$ each) were the representing categories and drawn the picture of the whole research demography. 
Table (4): Distribution of the study subjects according to their demographic profile $(n=67)$.

\begin{tabular}{|c|c|c|}
\hline Demographic items & No. 67 & $\%$ \\
\hline \multicolumn{3}{|l|}{ Age (years) } \\
\hline \multirow{3}{*}{$\begin{array}{l}60-<65 \\
65-70 \\
\geq 70\end{array}$} & 12 & 17.9 \\
\hline & 27 & 40.3 \\
\hline & 28 & 41.8 \\
\hline \multirow{2}{*}{$\begin{array}{l}\text { Min. - Max. } \\
\text { Mean } \pm \text { SD.\# }\end{array}$} & \multicolumn{2}{|c|}{$60.0-82.0$} \\
\hline & \multicolumn{2}{|c|}{$70.12 \pm 6.20$} \\
\hline \multicolumn{3}{|l|}{ Sex } \\
\hline \multirow{2}{*}{$\begin{array}{l}\text { Male } \\
\text { Female }\end{array}$} & 26 & 38.8 \\
\hline & 41 & 61.2 \\
\hline \multicolumn{3}{|l|}{ Marital status } \\
\hline \multirow{4}{*}{$\begin{array}{l}\text { Married } \\
\text { Widow } \\
\text { Single } \\
\text { Divorced } \\
\end{array}$} & 52 & 77.6 \\
\hline & 7 & 10.4 \\
\hline & 4 & 6.0 \\
\hline & 4 & 6.0 \\
\hline \multicolumn{3}{|l|}{ Educational level } \\
\hline \multirow{3}{*}{$\begin{array}{l}\text { Preparatory } \\
\text { Secondary } \\
\text { Higher education }\end{array}$} & 11 & 16.4 \\
\hline & 41 & 61.2 \\
\hline & 15 & 22.4 \\
\hline \multicolumn{3}{|l|}{ Job before retirement } \\
\hline \multirow{4}{*}{$\begin{array}{l}\text { Housewife } \\
\text { Employee } \\
\text { Business worker } \\
\text { Skilled worker }\end{array}$} & 8 & 11.9 \\
\hline & 39 & 58.2 \\
\hline & 11 & 16.4 \\
\hline & 9 & 13.4 \\
\hline \multicolumn{3}{|l|}{ Income } \\
\hline \multirow{2}{*}{$\begin{array}{l}\text { Enough } \\
\text { Not enough }\end{array}$} & 28 & 41.8 \\
\hline & 39 & 58.2 \\
\hline
\end{tabular}

\#SD: Standard deviation

Table (5) revealed that the most common oral health problems were tooth decay (64.2\%), followed by tooth plaque $(62.7 \%)$, tooth pain $(55.2 \%)$, and bad mouth odor $(50.7 \%)$. As regards oral hygienic behaviors, nearly three fifths $(59.7 \%)$ of the study subjects brushed their teeth regularly. Out of those perform regular brushing, $70 \%$ of them brushed their teeth once daily, for just one minute duration (82.5\%), with toothpaste containing fluoride $(72.5 \%)$. Few of the total sample practiced interdental cleaning either with dental floss or Miswak (29.8\%). Regarding the impact of oral health problems, a noticeable significant percent of the study subjects reported that their ability to drink hot/ cold fluids (40.3\%), mouth appearance $(40.3 \%)$, satisfaction with life $(32.8 \%)$, pronunciation $(28.4 \%)$, and mastication $(20.9 \%)$ were negatively affected by oral abnormalities. 
Table (5): Distribution of the study subjects according to their oral health problems, hygiene behaviors and the impact of oral abnormalities $(n=67)$.

\begin{tabular}{|c|c|c|}
\hline Items considering oral disorders, practices, and health & No.67 & $\%$ \\
\hline \multicolumn{3}{|l|}{ Presence of oral health problems\# } \\
\hline Tooth decay & 43 & 64.2 \\
\hline Tooth plaque & 42 & 62.7 \\
\hline Tooth pain & 37 & 55.2 \\
\hline Bad mouth odor & 34 & 50.7 \\
\hline Mouth ulcer & 24 & 35.8 \\
\hline Dry mouth & 15 & 22.4 \\
\hline Gum bleeding & 10 & 14.9 \\
\hline Tooth fracture & 9 & 13.4 \\
\hline Oral hygienic behaviors: & No.67 & $\%$ \\
\hline Regular tooth brushing & 40 & 59.7 \\
\hline Inter-dental cleaning (Use of dental floss, Use of Miswak) & 20 & 29.8 \\
\hline Water mouth rinsing & 7 & 10.5 \\
\hline Tooth brushing frequency & No.40 & $\%$ \\
\hline Once a day & 28 & 70.0 \\
\hline Twice a day & 9 & 22.5 \\
\hline More than twice a day & 3 & 7.5 \\
\hline Duration of tooth brushing & No.40 & $\%$ \\
\hline One minute & 33 & 82.5 \\
\hline Two minutes & 4 & 10.0 \\
\hline More than two minutes & 3 & 7.5 \\
\hline Type of toothpaste: & No.40 & $\%$ \\
\hline Use of toothpaste with fluoride. & 29 & 72.5 \\
\hline Use gargling lotion for mouthwash & 11 & 27.5 \\
\hline $\begin{array}{l}\text { Oral health problems have a negative impact on the } \\
\text { following aspects: \# }\end{array}$ & No.67 & $\%$ \\
\hline Drinking hot or cold fluids & 27 & 40.3 \\
\hline Mouth appearance & 27 & 40.3 \\
\hline Satisfaction with life & 22 & 32.8 \\
\hline Pronunciation & 19 & 28.4 \\
\hline Mastication & 14 & 20.9 \\
\hline
\end{tabular}

\# More than one response

Table (6) illustrated that the total mean percent score for health literacy in dentistry was (59.51 \pm 13.58) pre-implementation of the program which improved instantly postimplementation and at the end of third week interval $(75.05 \pm 10.13,70.51 \pm 12.02$ respectively), with an observed statistically significant difference $((\mathrm{P}=<0.001)$. Receptivity, utilization, support were the most progressed dimensions of health literacy in dentistry $(84.70$ 
$\pm 14.24,80.04 \pm 13.25,79.66 \pm 13.38$ respectively) instantaneously and after the period of second estimation post program $(76.49 \pm 21.27,74.07 \pm 17.59,81.16 \pm 13.12$ respectively $)$.

Table (6): Effect of applying educational program on health literacy in dentistry scale among the study subjects $(n=67)$.

\begin{tabular}{|c|c|c|c|c|c|}
\hline \multirow{2}{*}{ Oral health literacy subscales } & Pre & Immediately & 3 weeks & \multirow[b]{2}{*}{$\mathbf{F}$} & \multirow{2}{*}{$\mathbf{p}$} \\
\hline & Mean \pm SD. & Mean \pm SD. & Mean \pm SD. & & \\
\hline $\begin{array}{l}\text { Economic barrier } \\
\text { Total score } \\
\text { Mean score } \\
\% \text { score } \\
\end{array}$ & $\begin{array}{c}3.51 \pm 1.34 \\
1.75 \pm 0.67 \\
43.84 \pm 16.77 \\
\end{array}$ & $\begin{array}{c}3.97 \pm 1.23 \\
1.99 \pm 0.62 \\
49.63 \pm 15.38 \\
\end{array}$ & $\begin{array}{c}3.97 \pm 1.23 \\
1.99 \pm 0.62 \\
49.63 \pm 15.38 \\
\end{array}$ & $45.828^{*}$ & $<0.001^{*}$ \\
\hline \begin{tabular}{|l|} 
Communication \\
Total score \\
Mean score \\
$\%$ score \\
\end{tabular} & $\begin{array}{c}4.22 \pm 1.75 \\
2.11 \pm 0.87 \\
52.80 \pm 21.85 \\
\end{array}$ & $\begin{array}{c}6.28 \pm 0.88 \\
3.14 \pm 0.44 \\
78.54 \pm 11.05 \\
\end{array}$ & $\begin{array}{r}5.16 \pm 1.30 \\
2.60 \pm 0.62 \\
64.93 \pm 15.58 \\
\end{array}$ & $108.700^{*}$ & $<0.001^{*}$ \\
\hline \begin{tabular}{|l|} 
Utilization \\
Total score \\
Mean score \\
$\%$ score \\
\end{tabular} & $\begin{array}{c}4.67 \pm 1.54 \\
2.34 \pm 0.77 \\
58.40 \pm 19.27\end{array}$ & $\begin{array}{c}6.40 \pm 1.06 \\
3.20 \pm 0.53 \\
80.04 \pm 13.25 \\
\end{array}$ & $\begin{array}{c}5.93 \pm 1.41 \\
2.96 \pm 0.70 \\
74.07 \pm 17.59 \\
\end{array}$ & $97.062^{*}$ & $<0.001^{*}$ \\
\hline \begin{tabular}{|l} 
Access \\
Total score \\
Mean score \\
$\%$ score \\
\end{tabular} & $\begin{array}{c}5.00 \pm 1.53 \\
2.50 \pm 0.76 \\
62.50 \pm 19.09\end{array}$ & $\begin{array}{c}5.94 \pm 1.24 \\
2.97 \pm 0.62 \\
74.25 \pm 15.52\end{array}$ & $\begin{aligned} 5.79 & \pm 1.30 \\
2.90 & \pm 0.65 \\
72.39 & \pm 16.22\end{aligned}$ & $34.684^{*}$ & $<0.001^{*}$ \\
\hline \begin{tabular}{|l} 
Receptivity \\
Total score \\
Mean score \\
$\%$ score \\
\end{tabular} & $\begin{array}{c}5.10 \pm 2.02 \\
2.55 \pm 1.01 \\
63.81 \pm 25.20\end{array}$ & $\begin{array}{c}6.78 \pm 1.14 \\
3.39 \pm 0.57 \\
84.70 \pm 14.24\end{array}$ & $\begin{array}{c}6.12 \pm 1.70 \\
3.06 \pm 0.85 \\
76.49 \pm 21.27\end{array}$ & $75.619^{*}$ & $<0.001^{*}$ \\
\hline $\begin{array}{l}\text { Understanding } \\
\text { Total score } \\
\text { Mean score } \\
\% \text { score } \\
\end{array}$ & $\begin{array}{c}5.16 \pm 1.82 \\
2.58 \pm 0.91 \\
64.55 \pm 22.78 \\
\end{array}$ & $\begin{array}{c}6.28 \pm 1.55 \\
3.14 \pm 0.77 \\
78.54 \pm 19.32 \\
\end{array}$ & $\begin{array}{c}5.99 \pm 1.56 \\
2.99 \pm 0.78 \\
74.81 \pm 19.52 \\
\end{array}$ & $56.810^{*}$ & $<0.001^{*}$ \\
\hline \begin{tabular}{|l|} 
Support \\
Total score \\
Mean score \\
$\%$ score \\
\end{tabular} & $\begin{array}{c}5.66 \pm 0.96 \\
2.83 \pm 0.48 \\
70.71 \pm 12.03\end{array}$ & \begin{tabular}{|c|}
$6.37 \pm 1.07$ \\
$3.19 \pm 0.54$ \\
$79.66 \pm 13.38$ \\
\end{tabular} & $\begin{array}{c}6.49 \pm 1.05 \\
3.25 \pm 0.52 \\
81.16 \pm 13.12\end{array}$ & $31.550^{*}$ & $<0.001^{*}$ \\
\hline \begin{tabular}{|l|} 
Overall HeLD \\
Total score \\
Mean score \\
$\%$ score \\
\end{tabular} & $\begin{array}{c}33.33 \pm 7.61 \\
2.38 \pm 0.54 \\
59.51 \pm 13.58\end{array}$ & $\begin{array}{c}42.03 \pm 5.67 \\
3.00 \pm 0.41 \\
75.05 \pm 10.13\end{array}$ & $\begin{array}{c}39.45 \pm 6.77 \\
2.82 \pm 0.48 \\
70.51 \pm 12.02 \\
\end{array}$ & $317.941^{*}$ & $<0.001^{*}$ \\
\hline
\end{tabular}

F: F test (ANOVA) with repeated measures

*: Statistically significant at $\mathrm{p} \leq 0.05$

Table (7) mentioned that there was a highly statistically significant difference $(\mathrm{p}<0.001)$ in the whole mean percent score of oral health values of the study subjects and its subscales post in comparable with pre- the educational program. Concerns about the impact of oral health on appearance, importance of brushing behaviors, importance of retaining natural teeth were the most advanced oral health values' dimensions promptly after $(80.60 \pm 11.55$, $77.80 \pm 9.38,77.15 \pm 10.86$ respectively) and following 3 - week post-program span (71.39 \pm $11.81,62.41 \pm 10.63,64.09 \pm 11.48$ respectively). 
Table (7): Effect of applying educational program on oral health values scale among the study subjects $(n=67)$.

\begin{tabular}{|c|c|c|c|c|c|}
\hline \multirow{2}{*}{ Oral health values subscales } & Pre & Immediately & 3 weeks & \multirow{2}{*}{$\mathbf{F}$} & \multirow{2}{*}{$\mathbf{p}$} \\
\hline & Mean \pm SD. & Mean \pm SD. & Mean \pm SD. & & \\
\hline \multicolumn{6}{|l|}{$\begin{array}{l}\text { Importance of flossing } \\
\text { behaviors }\end{array}$} \\
\hline Total score & $10.58 \pm 1.56$ & $14.03 \pm 1.91$ & $13.21 \pm 1.71$ & \multirow{3}{*}{$281.153^{*}$} & \multirow{3}{*}{$<0.001^{*}$} \\
\hline Mean score & $2.65 \pm 0.39$ & $3.51 \pm 0.48$ & $3.30 \pm 0.43$ & & \\
\hline$\%$ score & $41.14 \pm 9.74$ & $62.69 \pm 11.97$ & $57.56 \pm 10.69$ & & \\
\hline \multicolumn{6}{|l|}{$\begin{array}{l}\text { Importance of seeking } \\
\text { professional dental care }\end{array}$} \\
\hline Total score & $22.64 \pm 4.31$ & $31.25 \pm 3.30$ & $27.22 \pm 3.66$ & \multirow{3}{*}{$571.379^{*}$} & \multirow{3}{*}{$<0.001^{*}$} \\
\hline Mean score & $2.83 \pm 0.54$ & $3.91 \pm 0.41$ & $3.40 \pm 0.46$ & & \\
\hline$\%$ score & $45.76 \pm 13.47$ & $72.67 \pm 10.31$ & $60.07 \pm 11.45$ & & \\
\hline \multicolumn{6}{|l|}{$\begin{array}{l}\text { Importance of brushing } \\
\text { behaviors }\end{array}$} \\
\hline Total score & $11.78 \pm 1.71$ & $16.45 \pm 1.50$ & $13.99 \pm 1.70$ & \multirow{3}{*}{$460.728^{*}$} & \multirow{3}{*}{$<0.001^{\prime}$} \\
\hline Mean score & $2.94 \pm 0.43$ & $4.11 \pm 0.38$ & $3.50 \pm 0.43$ & & \\
\hline$\%$ score & $48.60 \pm 10.71$ & $77.80 \pm 9.38$ & $62.41 \pm 10.63$ & & \\
\hline \multicolumn{6}{|l|}{$\begin{array}{l}\text { Importance of retaining } \\
\text { natural teeth }\end{array}$} \\
\hline Total score & $12.06 \pm 1.99$ & $16.34 \pm 1.74$ & $14.25 \pm 1.84$ & \multirow{3}{*}{$622.512^{*}$} & \multirow{3}{*}{$<0.001^{*}$} \\
\hline Mean score & $3.01 \pm 0.50$ & $4.09 \pm 0.43$ & $3.56 \pm 0.46$ & & \\
\hline$\%$ score & $50.37 \pm 12.45$ & $77.15 \pm 10.86$ & $64.09 \pm 11.48$ & & \\
\hline \multicolumn{6}{|l|}{$\begin{array}{l}\text { Importance of overall oral } \\
\text { health and appearance }\end{array}$} \\
\hline Total score & $22.76 \pm 3.60$ & $28.21 \pm 2.73$ & $24.94 \pm 3.34$ & \multirow{3}{*}{$421.214^{*}$} & \multirow{3}{*}{$<0.001^{*}$} \\
\hline Mean score & $3.25 \pm 0.51$ & $4.03 \pm 0.39$ & $3.56 \pm 0.48$ & & \\
\hline$\%$ score & $56.29 \pm 12.85$ & $75.75 \pm 9.76$ & $64.07 \pm 11.92$ & & \\
\hline \multicolumn{6}{|l|}{$\begin{array}{l}\text { Concerns about the impact of } \\
\text { oral health on appearance }\end{array}$} \\
\hline Total score & $10.16 \pm 1.46$ & $12.67 \pm 1.39$ & $11.57 \pm 1.42$ & \multirow{3}{*}{$231.326^{*}$} & \multirow{3}{*}{$<0.001^{*}$} \\
\hline Mean score & $3.39 \pm 0.49$ & $4.22 \pm 0.46$ & $3.86 \pm 0.47$ & & \\
\hline$\%$ score & $59.70 \pm 12.19$ & $80.60 \pm 11.55$ & $71.39 \pm 11.81$ & & \\
\hline \multicolumn{6}{|l|}{ Overall Oral Health Values } \\
\hline Total score & $89.99 \pm 10.64$ & $118.96 \pm 8.91$ & $105.18 \pm 9.89$ & \multirow{3}{*}{$1999.71^{*}$} & \multirow{3}{*}{$<0.001$} \\
\hline Mean score & $3.00 \pm 0.35$ & $3.97 \pm 0.30$ & $3.51 \pm 0.33$ & & \\
\hline$\%$ score & $49.99 \pm 8.86$ & $74.13 \pm 7.42$ & $62.65 \pm 8.24$ & & \\
\hline
\end{tabular}

F: F test (ANOVA) with repeated measures

*: Statistically significant at $\mathrm{p} \leq 0.05$

Table (8) signified that the study subjects had lower overall mean percent score $(35.95$ \pm 13.96 ) of self-efficacies for oral health before the conduction of the program in comparison with the mean percent score $(56.92 \pm 8.80,49.33 \pm 12.26$ respectively) after the two-program duration, with a statistically significant difference $(\mathrm{P}=<0.001)$. Personal beliefs and hygiene habits were the most upgraded aspects of oral self-efficacy in the adjacent (64.57 \pm 11.21 , $53.61 \pm 9.43$ respectively) and distant phase of program conduction $(54.95 \pm 12.71,50.68 \pm$ 12.68 respectively). 
Table (8): $\quad$ Effect of applying educational program on Geriatric Self- Efficacy Scale for Oral Health (GSEOH) among the study subjects $(n=67)$.

\begin{tabular}{|c|c|c|c|c|c|}
\hline Geriatric Self- Efficacy for & Pre & Immediately & 3 weeks & $\mathbf{F}$ & \\
\hline Oral Health subscales & Mean \pm SD & Mean \pm SD & Mean \pm SD & $F$ & $\mathbf{p}$ \\
\hline Dental visit & & & & & \\
\hline Total score & $4.70 \pm 2.10$ & $6.85 \pm 1.13$ & $5.60 \pm 1.78$ & & \\
\hline Mean score & $1.57 \pm 0.70$ & $2.28 \pm 0.38$ & $1.87 \pm 0.59$ & $153.495^{*}$ & $<0.001^{*}$ \\
\hline$\%$ score & $18.91 \pm 23.37$ & $42.79 \pm 12.57$ & $28.86 \pm 19.73$ & & \\
\hline Hygiene habits & & & & & \\
\hline Total score & $16.90 \pm 3.64$ & $20.87 \pm 2.26$ & $20.16 \pm 3.04$ & & \\
\hline Mean score & $2.11 \pm 0.45$ & $2.61 \pm 0.28$ & $2.52 \pm 0.38$ & $137.691^{*}$ & $<0.001^{*}$ \\
\hline$\%$ score & $37.06 \pm 15.15$ & $53.61 \pm 9.43$ & $50.68 \pm 12.68$ & & \\
\hline Personal beliefs & & & & & \\
\hline Total score & $19.97 \pm 3.87$ & $26.43 \pm 3.03$ & $23.84 \pm 3.43$ & & \\
\hline Mean score & $2.22 \pm 0.43$ & $2.94 \pm 0.34$ & $2.65 \pm 0.38$ & $320.838^{*}$ & $<0.001^{*}$ \\
\hline$\%$ score & $40.63 \pm 14.33$ & $64.57 \pm 11.21$ & $54.95 \pm 12.71$ & & \\
\hline Overall GSEOH & & & & & \\
\hline Total score & $41.57 \pm 8.38$ & $54.15 \pm 5.28$ & $49.60 \pm 7.35$ & & \\
\hline Mean score & $2.08 \pm 0.42$ & $2.71 \pm 0.26$ & $2.48 \pm 0.37$ & $341.321^{*}$ & $<0.001^{*}$ \\
\hline$\%$ score & $35.95 \pm 13.96$ & $56.92 \pm 8.80$ & $49.33 \pm 12.26$ & & \\
\hline
\end{tabular}

F: F test (ANOVA) with repeated measures

*: Statistically significant at $\mathrm{p} \leq 0.05$

Figures $(1,2,3)$ clarified that health literacy in dentistry is a predicting / independent factor for each of geriatric self- efficacy for oral health and oral health values in each period of the program.

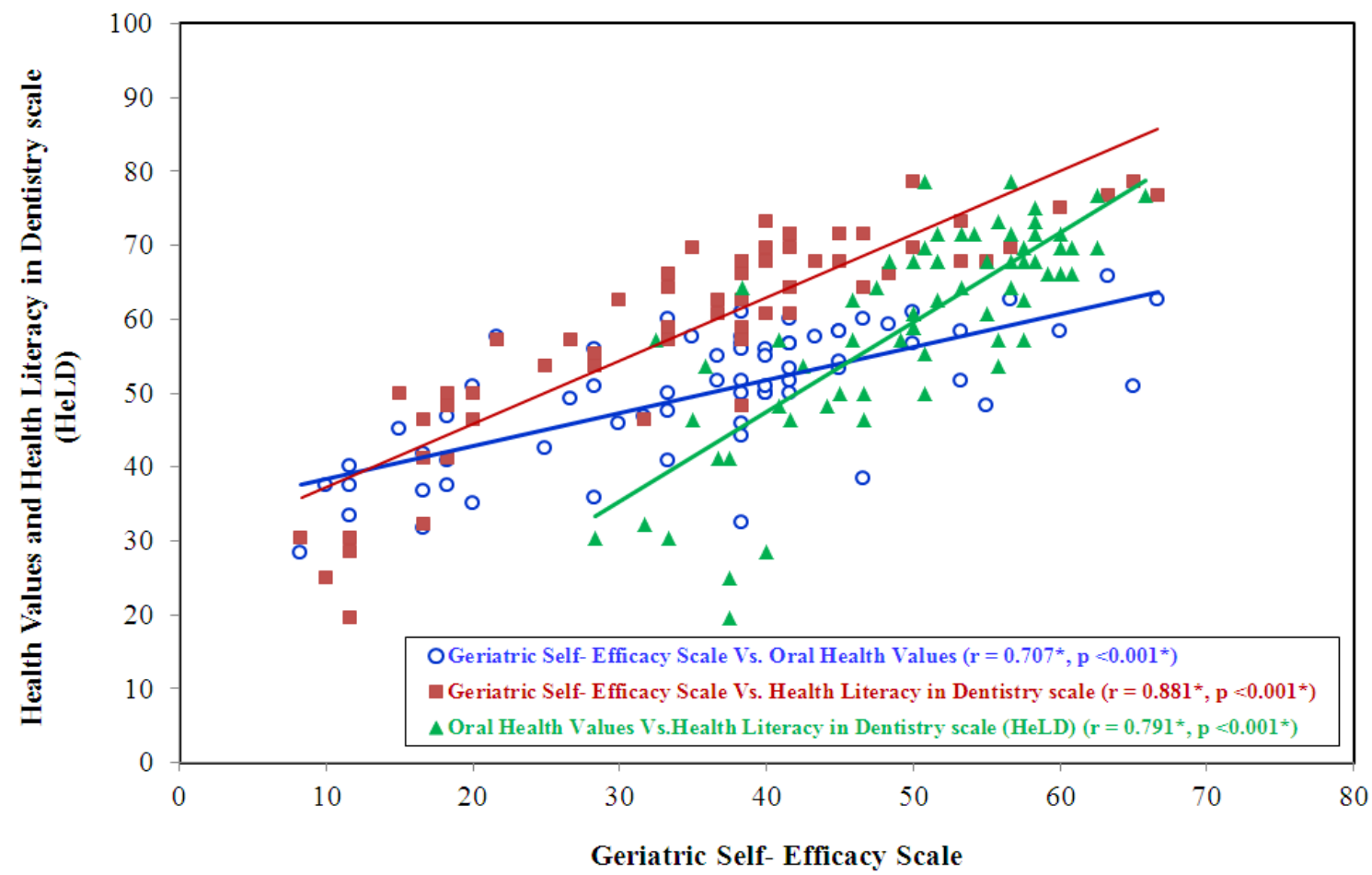

Figures (1): Correlation between oral health literacy, values, and oral self-efficacy in pre- application period of the educational program $(n=67)$. 


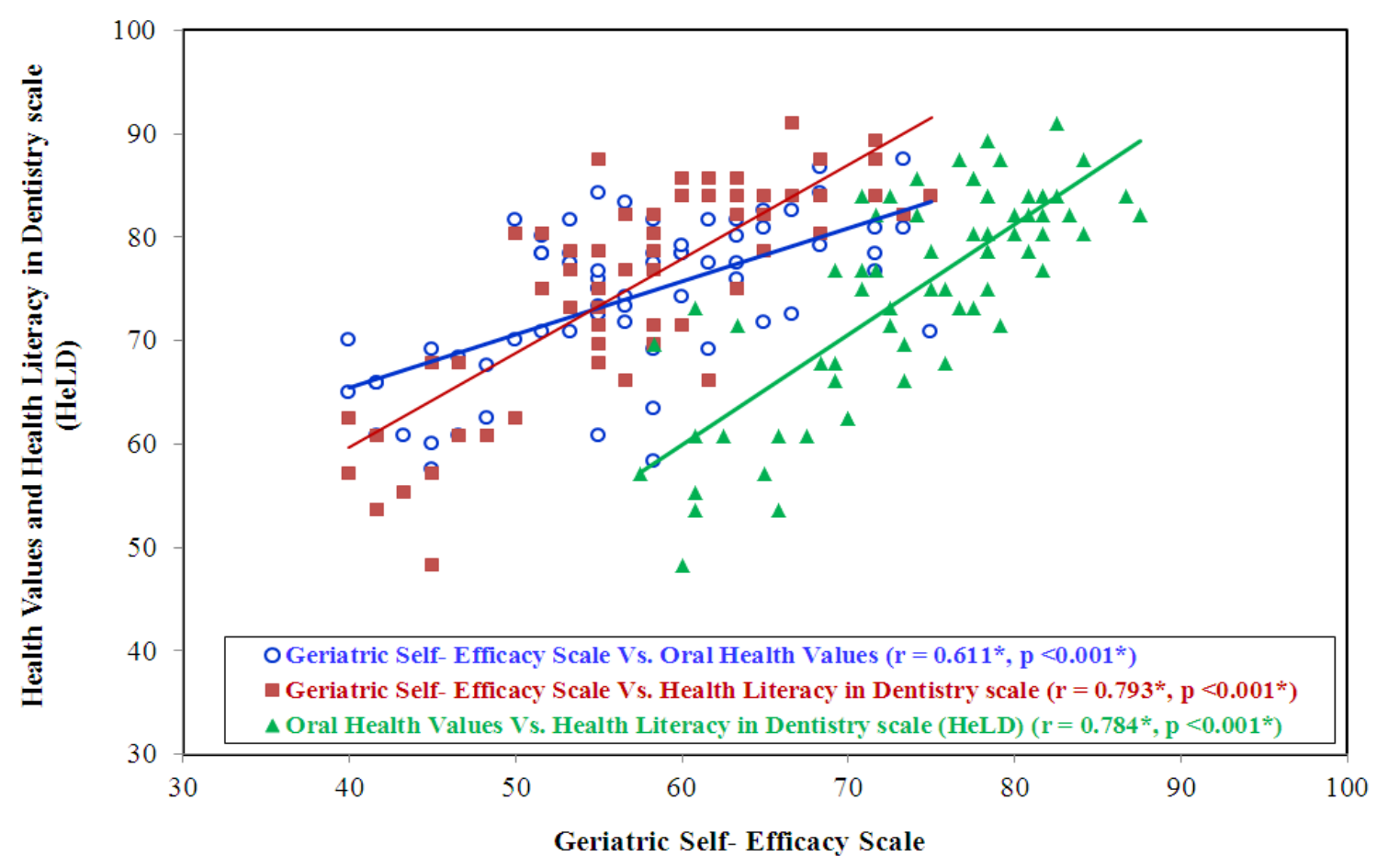

Figures (2): Correlation between oral health literacy, values, and oral self-efficacy in immediate application period of the educational program $(n=67)$.

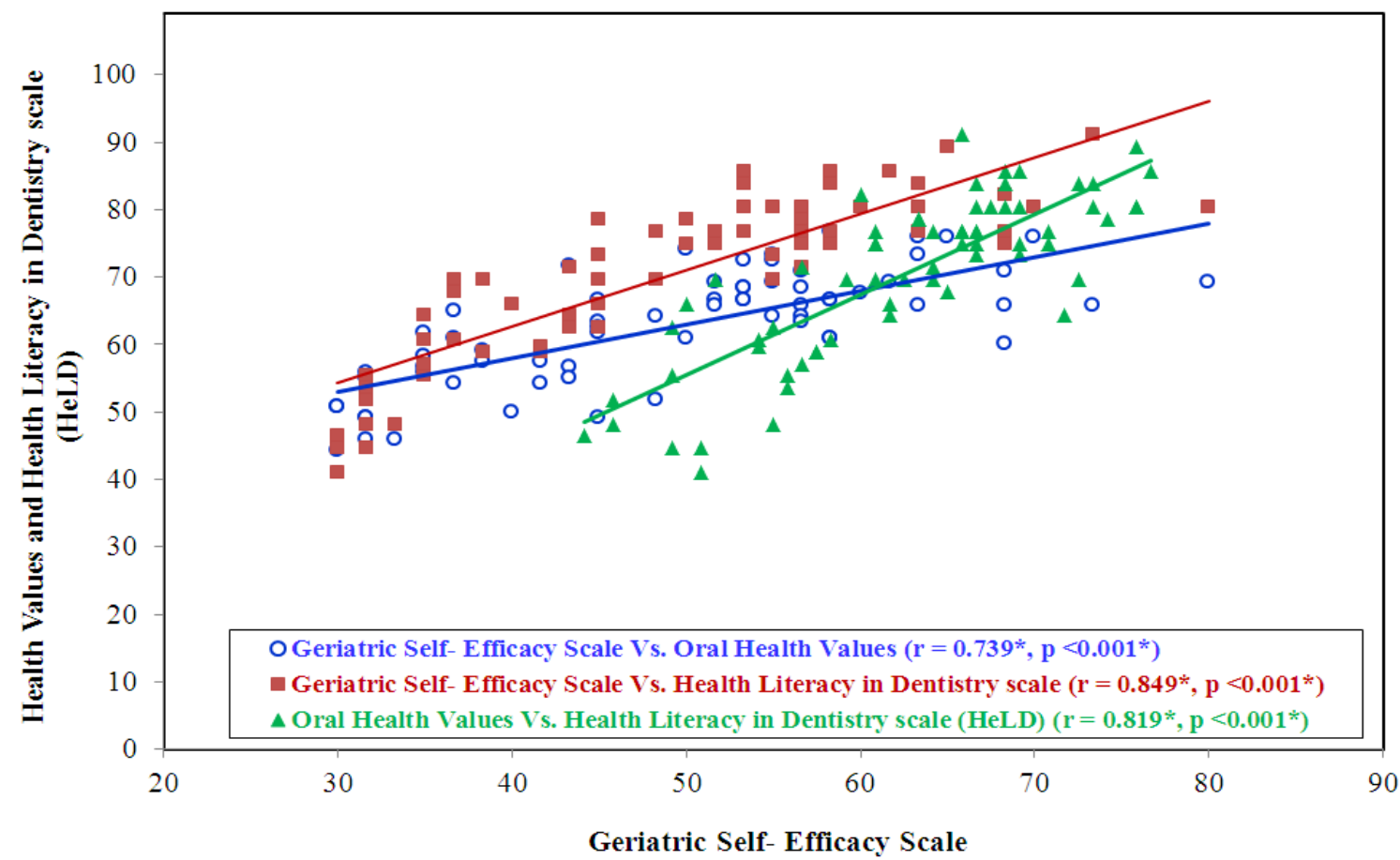

Figures (3): Correlation between oral health literacy, values, and oral self-efficacy in 3week application period of the educational program $(n=67)$.

r: Pearson coefficient

*: Statistically significant at $\mathrm{p} \leq 0.05$ 
The absolute value of $r$ : 0.00-0.19: "very weak"., 0.20-0.39: "weak", 0.40-0.59: "moderate", 0.60-0.79: "strong", 0.80-1.0: "very strong".

Table (9) noted that there is a strong positive significant correlation between oral health literacy, oral health values, and oral self-efficacy in pre-, immediately and 3-months after educational program.

Table (9): Linear regression for Health Literacy in Dentistry, Geriatric Self- Efficacy for Oral Health and Oral Health Values among the study subjects $(n=67)$

\begin{tabular}{|c|c|c|c|c|}
\hline \multirow{2}{*}{ 1- Pre period } & \multicolumn{4}{|c|}{ Health Literacy in Dentistry scale } \\
\hline & B & Beta & $\mathbf{t}$ & p \\
\hline \multirow{2}{*}{$\begin{array}{l}\text { Geriatric Self- Efficacy Scale } \\
\text { for Oral Health }\end{array}$} & 0.905 & 0.881 & $14.978^{*}$ & $<0.001^{*}$ \\
\hline & \multicolumn{4}{|c|}{$\mathrm{R}^{2}=\mathbf{0 . 7 7 5}, \mathrm{F}=\mathbf{2 2 4 . 3 3 3}^{*}, \mathrm{p}<0.001^{*}$} \\
\hline \multirow{3}{*}{ Oral Health Values Scale } & B & Beta & $\mathbf{t}$ & $\mathbf{p}$ \\
\hline & 0.516 & 0.791 & $10.420^{*}$ & $<0.001^{*}$ \\
\hline & \multicolumn{4}{|c|}{$\mathrm{R}^{2}=\mathbf{0 . 6 2 6}, \mathrm{F}=\mathbf{1 0 8 . 5 7 3}^{*}, \mathrm{p}<0.001^{*}$} \\
\hline \multirow{2}{*}{ 2- Immediately period } & \multicolumn{4}{|c|}{ Health Literacy in Dentistry scale } \\
\hline & B & Beta & $\mathbf{t}$ & $\mathbf{p}$ \\
\hline \multirow{2}{*}{$\begin{array}{l}\text { Geriatric Self- Efficacy Scale } \\
\text { for Oral Health }\end{array}$} & 0.689 & 0.793 & $10.484^{*}$ & $<0.001^{*}$ \\
\hline & \multicolumn{4}{|c|}{$\mathrm{R}^{2}=\mathbf{0 . 6 2 8}, \mathrm{F}=109.908^{*}, \mathrm{p}<0.001^{*}$} \\
\hline \multirow{3}{*}{ Oral Health Values Scale } & $\mathbf{B}$ & Beta & $\mathbf{t}$ & $\mathbf{p}$ \\
\hline & 0.574 & 0.784 & $10.173^{*}$ & $<0.001^{*}$ \\
\hline & \multicolumn{4}{|c|}{$\mathrm{R}^{2}=0.614, \mathrm{~F}=103.498^{*}, \mathrm{p}<0.001^{*}$} \\
\hline \multirow{2}{*}{ 3- 3 weeks period } & \multicolumn{4}{|c|}{ Health Literacy in Dentistry scale } \\
\hline & $\mathbf{B}$ & Beta & $\mathbf{t}$ & $\mathbf{p}$ \\
\hline \multirow{2}{*}{$\begin{array}{l}\text { Geriatric Self- Efficacy Scale } \\
\text { for Oral Health }\end{array}$} & 0.866 & 0.849 & $12.977^{*}$ & $<0.001^{*}$ \\
\hline & \multicolumn{4}{|c|}{$\mathrm{R}^{2}=\mathbf{0 . 7 2 2}, \mathrm{F}=168.415^{*}, \mathrm{p}<0.001^{*}$} \\
\hline \multirow{3}{*}{ Oral Health Values Scale } & B & Beta & $\mathbf{t}$ & $\mathbf{p}$ \\
\hline & 0.561 & 0.819 & $11.497^{*}$ & $<0.001^{*}$ \\
\hline & \multicolumn{4}{|c|}{$\mathrm{R}^{2}=\mathbf{0 . 6 7 0}, \mathrm{F}=132.187^{*}, \mathrm{p}<0.001^{*}$} \\
\hline
\end{tabular}

F,p: $f$ and $p$ values for the model $\mathrm{R}^{2}$ : Coefficient of determination B: Unstandardized Coefficients Beta: Standardized Coefficients t: t-test of significance *: Statistically significant at $\mathrm{p} \leq 0.05$

\section{Discussion}

Oral health is gaining global attention because it is closely related to the general health and well-being ${ }^{[7]}$. With mounting evidence linking oral health to common chronic diseases and increasing costs for management of oral-related comorbidities, gerontological nurses and geriatric physicians caring for older adults need to close the gap between research and practice ${ }^{[24]}$. Though there is much research that explores the use of oral management with older adults, there are very scarce research that investigates health literacy, value, and selfefficacy in areas of their oral interventions or use advanced technology such as smart phones applications for oral teaching directed to this age-sector ${ }^{[23]}$. Additionally, data on the oral health status and treatment needs of the elderly in most African countries are insufficient ${ }^{[30]}$ 
The present study is the first in Egypt to directly focus on such studied variables and develop a comprehensive digital educational program in Arabic-version teaching the concept of oral interventions via smart phones applications to older adults and later determining the effect of such interventions posed. The present research gave a suggestion that several critical factors worked together to establish the poor oral health among elderly community dwellers. The adding in this research goes beyond the traditional factors to more explore and emphasize on aspects concerning elders' skills, values, beliefs, oral literacy levels and confidence in oral behavioral changes to enforce their oral practice till the stage of being normative habitual behaviors. We followed a new approach in our research that we invited family members and significant others to be involved in teaching so they can be oriented earlier with their older member's oral health needs, to be a source of encouragement, and to be a main source of help in case of dependence.

Among the primarily factor searched in this study is the elders' oral health literacy, with lower overall mean percent score $(59.51 \%)$, especially in areas of economy (43.84\%), communication (52.80\%), and utilization (58.40\%). This finding supported with literature which confirmed lower oral literacy among elders especially medically underserved ones. Oral preventive and management services in Egypt is expensive, comparable with payment standard of elders after retirement, which reflect negatively on their utilization of oral services. Additionally, these services provided mainly via health insurance clinics with long waiting list, less quality service and far distance. Oral literacy is much broader than just knowledge. It not only includes the ability to apply certain skills to health situations such as understanding instructions on prescriptions, appointments, brochures, directions or negotiate complex health care systems, but also on the ability to manage effective clear communication between health care dental professionals and their patients. This process is impaired in our community in which dentists or nurses may be not considered the special oral needs of elders; many of them with chronic illnesses (due to certain oral disorders in origin) and are sensory deprived, in addition to impaired mental and functional capabilities, resulting in impaired communication and utilization as well. Studies conducted in Tanzania (2016) and USA (2014) notified a quite low oral health knowledge among older adults about dental health ${ }^{[15,31]}$. At both two periods followed conduction of the educational program in this study, there was a profound improvement in total literacy percent scores $(75.05 \%, 70.51 \%$ respectively). Although oral literacy in not investigated in specific, the most astonishing data reported recently in Egypt (2018), that providing oral educational program is effective in improving oral health knowledge and subsequent oral health-related quality of life among community-dwelling elderly ${ }^{[32]}$.

The same previous picture of lower rate was observed among the overall mean percent score of oral health values $(49.99 \%)$, before commencing the program mainly in the dimensions of importance of flossing behaviors (41.14\%), seeking professional dental care $(45.76 \%)$, brushing behaviors $(48.60 \%)$, and retaining of natural teeth $(50.37 \%)$. This may be back to the elders' point of view in considering poor teeth conditions as a normal consequence of old age course that should be accepted as an outcome of associated frailty, so no actions could be made to reverse or manage oral health problems. The studied elders also expressed mouth rinse instead of brushing or flossing as a custom. As a result of lack of belief in the 
worthlessness of dental visit or in the importance of oral health and oral care, besides highcost services; they choice to preserve their energy and income for other life purposes. With the same line, Chinese older adults in a study conducted in (1999) expressed doubt in their ability to keep their natural teeth for life and felt that dental problems were inevitable at old age. Most of them believed that nothing they can do to prevent tooth loss, even if they clean their teeth regularly. Added to that, they resorted to traditional remedies instead of dental treatment by health professionals for dental problems ${ }^{[33]}$. Qualitative study conducted in EastNetherlands, Germany (2013) asserted that most older adults with complete or partial dentures did not see a dentist anymore, although they complained of uncomfortable and loose dentures, loose teeth, or painful teeth ${ }^{[34]}$. Griffin et al., (2012) agreed with such approach and further underlined that older adults are more likely to report lower perceived need for dental care utilization, supported by the fact that $48.2 \%$ of older adults aged 60-69 years had 1-15 natural teeth only as an average ${ }^{[12]}$. It has been well-documented that oral health education program serves as a tool to modify older adults' beliefs about dental health, and lead to adoption of favorable oral - maintaining behaviors contributing to better oral wellbeing ${ }^{[35]}$. So, it seems reasonable to find a higher post intervention of oral health value comparing to pre- assessment with significant differences in the mean scores through the whole interventional phases, especially concerns about appearance $(80.60 \%)$.

In the present study, the most contributing risk of lowered oral self-efficacy patterns (35.95\%) were those concerning with dental visit (18.91\%) and hygiene habits $(37.06 \%)$ than other different domains. Poor knowledge about dental problems, and its seriousness, perceived difficulty in practice oral preventive behaviors, lack of elders' valuing and motivation toward oral protective methods, in addition to their negative attitude toward oral prevention were among the most significant predictors of such result. Most studied older adults mentioned that visiting the dental clinic was only either to relieve intolerable pain or to treat an emergency dental problem. This result agreed with a study done in China by Pirograd \& Keeratisiroj, (2019) which revealed that at post-test period, the intervention group had an average score of self-efficacy expectation and dental health care behaviors more than pre-test group and the difference was statistically significant $(p<0.001)^{[36]}$. About half of American dentate adults aged 65 years and older had a dental visit only once a year according to the study results of Lowe \& Rossopoulos (2018) ${ }^{[37]}$. Poor hygienic habits clarified by Niesten et al., study (2013), in which German older people with physical disabilities lacks self-efficacy beliefs regarding oral hygiene practices and do not appreciate their abilities in related performance ${ }^{[34]}$. Lolita et al., (2015) further confirmed that $19.7 \%$ of older adults in Cameroon had never brushed their mouth ${ }^{[30]}$. It was expected to find elders' higher mean score of personal beliefs dimension (64.57\%) after conducting the educational sessions in the current study, compared to the rest. In other words, the successful improvement of the studied participants beliefs acts as an influencing method for higher self-confidence. This mean that once it upgraded, other aspects of self-efficacy will improve consequently.

A strong positive significant correlation between oral health literacy, values and oral self-efficacy at the three study periods was basically confirmed. The impact of poor oral literacy on the perceived ability of the elderly to control oral problems episodes or to manage 
them is profound. It negatively affects elders' perception of the degree of contentment with and capability to perform and control different facets of one's oral health. It is true that cultural traditions affect to the large extent the perception of such problems and its management. Our society perceive oral disorders in old age as problems that are largely unavoidable, or that maintain oral wellbeing for older adults is not a matter of priority. These perceptions can force older adults to adopt poor oral lifestyle and relinquish preventive participation with a resulting of impaired perception of ability to control or manage such event. Older adults' attitude on how they handle, will influence the methods of such problemavoidance behaviors. This better emphasized through mobile phones' applications which applied in our study as older adults can review easily pre-discussed theoretical and practical contents at any needed times, so mobiles act as a successful reference. Costless mobiles application facilitates communication and feedback between all parties of the program, so they promote continuous support and connection. A systemic review (2017) suggested that computer-aided learning in oral health has positive impacts on knowledge, attitude, behavior, and overall oral health through synthesis of data ${ }^{[23]}$. Mariino et al., (2004) was successful in prove that immigrant older adults in Australia who received community-based oral health promotion program had better oral knowledge, attitudes, as well as self-reported oral hygiene practices and use of oral services ${ }^{[35]}$. Borreani et al., study (2008) recommended that just reducing costs or providing more oral care to older people would not be effective enough in encouraging elders to use oral services, and that their oral health values, beliefs, and selfreliance need to be emphasized ${ }^{[38]}$.

It could be acceptable that the self-reported improvement was declined in the follow up period due to memory changes, especially short-term, associated with aging process. So, we recommend the importance of continuous reinforcement for improving practice. Gerontological nurses and geriatric physicians should empower geriatric' oral literacy, values and self-confidence in relation to dental care at recommended standards and mobilize strategies that struggle hindrances of performance, rather than just affirming the risks of indolence or the profits of oral self-attendance.

\section{Conclusion}

The findings confirmed the hypotheses of the current study that the application of mobile-based oral care implementation is elegantly effective in upgrading the studied variables with an observed statistically differences among the constructs prior, immediately and a 3-week follow up. This improvement slightly regretted over time but still better than before. Our research provided a valuable conclusion through the proved strong positive relationship found between all the studied variables across whole study phases. In comparing pre-test versus post-test, improvements in personal beliefs of self- efficacy, the impact of oral health on appearance of health value, and receptivity of oral literacy were the configuring pictures among a higher significant percent. The findings support existing literature that using digital-based oral practice health education is a factor in better oral health for older adults. 


\section{Recommendations:}

- Digital or e-health interventions to prevent or rectify oral and teeth problems of older adults should be wide-ranging and multi-faceted to be conducted via the social network and invest in mobile health clinics. The importance of regular oral health checks for the elderly needed to be widely promoted in the community and reinforced by gerontological nurses, geriatricians, and other health professionals.

- Design a preventive program to target older adults living in Egypt, through increasing access and minimize barriers to treatment for elderly with low financial standard and collecting systematic data on oral health status as well as general medical condition to be monitored and included in national oral health plans for older adults.

- Recommended usage of modifiable technological aiding devices for physically or mobility-limited older adults as an electronic toothbrush with a wide, greppable handle or floss holders/interdental cleaners to clean between teeth, can help promote their optimal maintenance of oral hygiene.

- Special consideration is focused on dentate older adults with cognitive limitations that making a challenged communication during the dental appointment, decreased ability to engage in oral care or follow instructions. Reassurance, frontal approach, nonverbal contact, simple instructions, and short sentences are recommended. Education as well to their caregivers to use techniques for resistive oral health behaviors (Bridging, Chaining, Hand over hand, Distraction, and Rescuing) and to consistently sure of following two or more times of oral care routine using battery-operated toothbrush and dental practice of any removable prosthetic devices.

- Special management should be approached to age-induced sensory limitations affected dental care so large print on prescription bottles, orientation before starting to use handpiece dental equipment, and written and illustrated materials explained dental information, procedures, and instructions should be accommodated.

\section{Acknowledgement}

The authors wish to offer sincere thanks to all geriatric club staff and community dwelled older adults and their family members who participated in the study. Great thanks are also due to the panel of Prosthodontics, Periodontics, and Endodontics departments, Faculty of dentistry, Alexandria University sharing in study validity; to club manager who facilitated the study; to all who provided statistical and research methods advice, participated in the sessions or offered training and advice on aspects of the study. Many thanks are also extended to the Ministry of Social Solidarity of Egypt and Faculty of Nursing and Medicine, Alexandria University that supported such research program.

\section{Conflict of Interest}

The authors have declared no conflict of interest.

\section{Published by : N I L E S}




\section{Funding}

This research did not receive any specific grant from funding agencies in the public, commercial, or not-for-profit sectors.

\section{References}

1. World Health Organization (WHO). Active ageing: A policy framework. Geneva, Switzerland: WHO; 2002.

2. Bernabe E, Marcenes W, Hernandez CR, Bailey J, Abreu LG, Alipour V, et al. Global, Regional, and National Levels and Trends in Burden of Oral Conditions from 1990 to 2017: A Systematic Analysis for the Global Burden of Disease 2017 Study. J Dent Res. 2020;99(4):362-73.

3. Al-Nasser L, Lamster IB. Prevention and management of periodontal diseases and dental caries in the older adults. Periodontology. 2020;84(1):69-83.

4. World Health Organization (WHO). Oral Health: Information sheet. Geneva, Switzerland: WHO; 2012.

5. Nazir MA. Prevalence of periodontal disease, its association with systemic diseases and prevention. Int J Health Sci (Qassim). 2017;11(2):72-80.

6. Razak PA, Richard KM, Thankachan RP, Hafiz KA, Kumar KN, Sameer KM. Geriatric oral health: a review article. J Int Oral Health. 2014;6(6):110-6.

7. Wong FMF, Ng YTY, Leung WK. Oral Health and Its Associated Factors Among Older Institutionalized Residents-A Systematic Review. Int J Environ Res Public Health. 2019;16(21).

8. Gil-Montoya JA, de Mello AL, Barrios R, Gonzalez-Moles MA, Bravo M. Oral health in the elderly patient and its impact on general well-being: a nonsystematic review. Clin Interv Aging. 2015;10:461-7.

9. Maeda K, Mori N. Poor oral health and mortality in geriatric patients admitted to an acute hospital: an observational study. BMC Geriatr. 2020;20(1):26.

10. Nazir MA, Izhar F, Akhtar K, Almas K. Dentists' awareness about the link between oral and systemic health. J Family Community Med. 2019;26(3):206-12.

11. Göstemeyer G, Baker SR, Schwendicke F. Barriers and facilitators for provision of oral health care in dependent older people: a systematic review. Clin Oral Investig. 2019;23(3):979-93.

12. Griffin SO, Jones JA, Brunson D, Griffin PM, Bailey WD. Burden of oral disease among older adults and implications for public health priorities. Am J Public Health. 2012;102(3):411-8.

13. Hosseinpoor AR, Itani L, Petersen PE. Socio-economic inequality in oral healthcare coverage: results from the World Health Survey. J Dent Res. 2012;91(3):275-81.

14. Al-Sinaidi AA. Periodontal health and oral hygiene practice of elderly Saudis living at Riyadh Nursing Home. King Saud University Journal of Dental Sciences. 2012;3(1):1-5.

15. McQuistan MR, Qasim A, Shao C, Straub-Morarend CL, Macek MD. Oral health knowledge among elderly patients. J Am Dent Assoc. 2015;146(1):17-26. 
16. Das D, Menon I, Gupta R, Arora V, Ashraf A, Ahsan I. Oral health literacy: A practical strategy towards better oral health status among adult population of Ghaziabad district. J Family Med Prim Care. 2020;9(2):764-70.

17. Boynes S, Nelson J, Diep V, Kanan C, Pedersen DN, Brown C, et al. Understanding value in oral health: the oral health value-based care symposium. J Public Health Dent. 2020;80 Suppl 2:S27-s34.

18. Listl S. Value-Based Oral Health Care: Moving Forward With Dental Patient-Reported Outcomes. J Evid Based Dent Pract. 2019;19(3):255-9.

19. Schwarzer R, Antoniuk A, Gholami M. A brief intervention changing oral self-care, self-efficacy, and self-monitoring. Br J Health Psychol. 2015;20(1):56-67.

20. Zhou G, Sun C, Knoll N, Hamilton K, Schwarzer R. Self-efficacy, planning and action control in an oral self-care intervention. Health Educ Res. 2015;30(4):671-81.

21. Mariño RJ, Marwaha P, Barrow SY. Web-based oral health promotion program for older adults: Development and preliminary evaluation. Int J Med Inform. 2016;91:e9-e15.

22. Catteau C, Faulks D, Mishellany-Dutour A, Collado V, Tubert-Jeannin S, Tardieu C, et al. Using e-learning to train dentists in the development of standardised oral health promotion interventions for persons with disability. Eur J Dent Educ. 2013;17(3):143-53.

23. Ab Malik N, Zhang J, Lam OL, Jin L, McGrath C. Effectiveness of computer-aided learning in oral health among patients and caregivers: a systematic review. J Am Med Inform Assoc. 2017;24(1):209-17.

24. Mohsen MM, Abd EL Megeed HA, Elsayed DM, Abd El-Rhaman ME. Quality of dental care among elderly in Benha city. J Nurs Health Sci. 2017;6(4):64-76.

25. Jones K, Parker E, Mills H, Brennan D, Jamieson LM. Development and psychometric validation of a Health Literacy in Dentistry scale (HeLD). Community Dent Health. 2014;31(1):37-43.

26. Jones K, Brennan D, Parker E, Jamieson L. Development of a short-form Health Literacy Dental Scale (HeLD-14). Community Dent Oral Epidemiol. 2015;43(2):143-51.

27. Edwards CB. Development and validation of an oral health values scale: West Virginia University; 2014.

28. Ohara Y, Yoshida N, Kawai H, Obuchi S, Yoshida H, Mataki S, et al. Development of an oral health-related self-efficacy scale for use with older adults. Geriatr Gerontol Int. 2017;17(10):1406-11.

29. Palati S, Ramani P, Shrelin HJ, Sukumaran G, Ramasubramanian A, Don KR, et al. Knowledge, Attitude and practice survey on the perspective of oral lesions and dental health in geriatric patients residing in old age homes. Indian J Dent Res. 2020;31(1):22-5.

30. Michele Lolita Y, Ashu Michael A, Hubert N, Florence D, Jacques B. Oral Health Status of the Elderly at Tonga, West Region, Cameroon. Int J Dent. 2015;2015:820416.

31. Minja I, Astrøm A, Masalu J. Prevalence and distribution of oral health knowledge according to sociodemographic, behavioural and clinical characteristics in selected coastal districts of Tanzania. Tanzan J Health Res. 2016;18:1-13. 
32. Eman Shokry AA, Rehab Adel M, Rashad AE-sA. Educational program to improve quality of life among elderly regarding oral health. Future Dental Journal. 2018;4(2):211-5.

33. Kwan SY, Holmes MA. An exploration of oral health beliefs and attitudes of Chinese in West Yorkshire: a qualitative investigation. Health Educ Res. 1999;14(4):453-60.

34. Niesten D, van Mourik K, van der Sanden W. The impact of frailty on oral care behavior of older people: a qualitative study. BMC Oral Health. 2013;13:61.

35. Mariño R, Calache H, Wright C, Schofield M, Minichiello V. Oral health promotion programme for older migrant adults. Gerodontology. 2004;21(4):216-25.

36. Pirograd P, Keeratisiroj O. The Effects of a Self-Efficacy Application Program on Dental Health Care Behavior Among Older Adults in an Elderly Club, Lablae District, Uttaradit Province. J Health Educat. 2019;42(2):110-22.

37. Lowe O, Rossopoulos E. Assessment of oral health status of elderly population living in residential care facilities. Ann Dent Oral Health. 2018;1:1-4.

38. Borreani E, Wright D, Scambler S, Gallagher JE. Minimising barriers to dental care in older people. BMC Oral Health. 2008;8:7. 